\title{
Arbor
}

\section{El auge del turismo europeo en la España de los años sesenta}

\author{
Esther M. Sánchez Sánchez
}

Arbor CLXX, 669 (Septiembre 2001), 201-224 pp.

Uno de los motores del desarrollo económico y la apertura exterior de España durante la década de los años sesenta fue el auge sostenido del turismo extranjero. La entrada de divisas ligada a la afluencia de veraneantes se tradujo en un impulso considerable al proceso de modernización del país. Al mismo tiempo, el encuentro personal directo entre turistas y residentes facilitó el acceso de la población española educada bajo el franquismo a las pautas de actuación social, moral y cultural de los países de su entorno geográfico. Este artículo analiza la contribución del turismo a la inserción de España en la órbita de los países capitalistas y democráticos del mundo occidental, al servir de factor legitimador del sistema político, embajador de una imagen nacional y acelerador del crecimiento económico, el cambio sociológico y la integración institucional del país.

\section{Evolución del turismo extranjero con destino a España}

El registro de los primeros viajes a España por razones «turísticas», esto es, con fin de disfrute vacacional y sin ánimo de lucro, se remonta al último tercio del siglo XIX. Los escasos integrantes de estas partidas pioneras formaban dos grupos muy diferentes entre sí: unos, aventureros, eruditos y autores románticos, recorrieron la geografía ibérica en busca de un paisaje exótico que inspiró novelas y cuadernos de 
viaje; otros, procedentes de medios opulentos, prefirieron disfrutar de los efectos terapéuticos de las estaciones termales de la costa cantábrica o de los balnearios del interior, bien por prescripción médica, bien por simple ansia de recreo. Su llegada fue pareja a un cierto impulso en el desarrollo de las infraestructuras, a la mejora urbanística de los núcleos de mayor demanda y a la puesta en funcionamiento de diversos organismos para la regulación y estímulo del sector. En este último aspecto, destacó la creación de las primeras instituciones estatales (Comisión Nacional de Turismo en 1905, Comisaría Regia de Turismo en 1911, Patronato Nacional de Turismo en 1928) y la proliferación de «sociedades de excursionistas» en las distintas ciudades españolas (Centro Excursionista de Cataluña en Barcelona, 1876; Sociedad Española de Excursiones en Madrid, 1893; Sociedad Castellana de Excursionismo en Valladolid, 1903). Pero, en los albores del siglo $\mathrm{XX}$, la entrada de visitantes extranjeros en España continuaba siendo minoritaria. El resultado de la iniciativa estatal y privada no fue sino un cierto incremento de los índices del turismo interior, sobre todo entre las clases aristocráticas cercanas a la familia real y entre los académicos y hombres políticos más relevantes del momento.

Con las dos guerras mundiales y la guerra civil española, el turismo quedó reducido a su mínima expresión. Al término de la segunda guerra mundial, los países beneficiarios del Plan Marshall consiguieron en breve remontar la destrucción de sus infraestructuras, cubrir las necesidades vitales de su población y forjar un ahorro interno que se tradujo en una ola creciente de desplazamientos. A medida que el turismo alcanzaba a capas más amplias de la población, sus antiguas motivaciones y destinos experimentaban sensibles mutaciones. Con los avances en el campo de la medicina y la carestía económica derivada del enfrentamiento bélico, las estaciones termales y balnearios entraron en un proceso de decadencia que supuso el desmantelamiento de buena parte de sus instalaciones. Los habitantes de la nueva Europa reconstruida y en plena expansión comenzaron a demandar sol y playas cálidas. Pero, en esos años, sus miras se dirigieron en prioridad hacia las costas mediterráneas de Italia y Francia.

En España, los estragos de la guerra civil, la hostilidad exterior y la autarquía impuesta por el nuevo régimen forzaron un aislamiento y una penuria económica que iba a retrasar durante casi dos décadas la enorme tarea de la reconstrucción y modernización del país. Sólo las capas adineradas, generalmente cercanas a los vencedores, lograban disponer de carburante o de los escasos medios de transporte que seguían funcionando en condiciones mínimas de seguridad, velocidad 
El auge del turismo europeo en la España de los años 60

y confort. También se limitaba a esos sectores la capacidad para superar con éxito el entramado de formalidades burocráticas y policiales exigidas en los pasos fronterizos: pasaportes, visados, salvoconductos, autorizaciones de zona, cartillas de abastecimiento para extranjeros, bonosgasolina, impuestos de circulación... Por su parte, la propaganda oficial optó por la promoción del patrimonio histórico-monumental, testigo de tiempos gloriosos, y por el fomento de actividades que, como la caza y la pesca, estuviesen orientadas a la captación de minorías acomodadas que no representaran ningún peligro ni amenaza para el nuevo régimen.

El tráfico de fugitivos, exiliados y emigrantes produjo, sin embargo, un movimiento de cierta intensidad en los principales puestos fronterizos del país. Esta circunstancia favoreció el nacimiento de algunas agencias de viajes que fueron incluso capaces de obtener, con procedimientos a veces no demasiado claros, una rentabilidad económica suficiente para subsistir sin pérdidas hasta enlazar con la explosión turística de los años sesenta.

Tras el fin del aislamiento internacional del régimen franquista, las infraestructuras y medios de comunicación pudieron beneficiarse de la ayuda exterior de los Estados Unidos (en el marco de los Convenios de 1953), de los organismos internacionales (sobre todo la OECE y el FMI) y de algunos países europeos con los que España mantenía acuerdos bilaterales (así Francia). Entre esta serie de aportaciones exteriores cabe destacar la asistencia norteamericana. La cooperación técnica y militar entre España y los Estados Unidos favoreció la expansión de sectores fundamentales en el campo turístico. Sirva de ejemplo el sector de la aviación: los primeros reactores que pasaron a formar parte de la flota de Iberia en 1961 fueron los Douglas DC-8 cedidos por los Estados Unidos. En 1959 se firmó un convenio entre la International Cooperation Administration -ICA- y la Oficina Española para las Relaciones con Norteamérica, por el cual España recibió un crédito de 122,5 millones de pesetas dirigido en exclusividad al desarrollo del sector turístico. En 1962 se gestionó un nuevo préstamo de 200 millones de pesetas, a los que se agregó un crédito de 100.000 dólares aportados por la ICA para la propaganda turística de España en Estados Unidos ${ }^{1}$. El desembarco de los norteamericanos también sirvió para la llegada a España de la multinacional hotelera Hilton, que introdujo un nuevo modelo de gestión de gran influencia en la hostelería española de los años sesenta ${ }^{2}$. A la ayuda exterior se unió el cierre de una larga etapa de autarquía económica, tras la entrada de los tecnócratas en el gobierno y la puesta en marcha del plan de 
estabilización de 1959. El restablecimiento de la disciplina financiera, la fijación de un sistema monetario de cambios realistas, la creciente liberalización del comercio exterior y el abandono progresivo de la rigidez intervencionista jugaron en beneficio de la entrada de visitantes y divisas.

Pronto, el boom del turismo internacional llegó a España y adquirió caracteres de una magnitud extraordinaria. En 1951 se registró el primer millón de visitantes y los incrementos absolutos fueron muy deprisa: 2.522 .402 en $1955,6.113 .255$ en $1960,14.251 .428$ en 1965 , 24.105 .312 en 1970 y 30.122 .478 en 1975. Según los datos aportados por las estadísticas oficiales, en 20 años el número de visitantes se había multiplicado por 12. Con los ingresos había ocurrido algo equivalente: los 296,5 millones de dólares registrados en 1960 se habían multiplicado por 10 en 1973, alcanzando la cifra de 3.216,1 millones. Llegaba a España el turismo contemporáneo, llamado comúnmente de masas. A diferencia del turismo de épocas anteriores, patrimonio exclusivo de minorías, se caracterizó por la implicación de amplios sectores de población y potencialmente de la sociedad en su conjunto.

En poco tiempo, España se situó a la cabeza de los países tradicionales de recepción turística en Europa: en 1952 logró superar a Francia y en 1964 a Italia, alzándose como líder del turismo mundial. Pese a la mejora progresiva del nivel de vida de la población española, durante la década de los años sesenta el turismo interior mantuvo un volumen sensiblemente inferior al del turismo extranjero. Europa fue la gran emisora de turistas hacia España, con un porcentaje medio anual del $80 \%$ del total de las entradas entre 1961 y 1970. Francia constituyó el más amplio mercado de captación, con una media del $48 \%$ del total europeo para el mismo intervalo. La distancia con respecto al resto de los países de Europa occidental fue considerable. En 1965, por ejemplo, Francia aportó 6.441.027 de visitantes en el total de entrados por nacionalidad, con lo que superó ampliamente a los dos países que la seguían en el ranking, Gran Bretaña y Alemania, con 1.359.996 y 1.046.657 de turistas respectivamente ${ }^{3}$.

¿Cuál es la realidad que está detrás de estas cifras? ¿En qué circunstancias los poderes públicos se consideraron con licencia para pregonar el «milagro»? ¿Cuáles fueron, en definitiva, los factores explicativos de este auge? Pueden agruparse en tres grandes bloques: en primer lugar, los atractivos naturales y coyunturales del país; en segundo lugar, la política de regulación y promoción turística puesta en práctica por el régimen franquista, $y$, en tercer aunque no último lugar, la influencia favorable del contexto de crecimiento económico y cambio social de Europa occidental. 
El auge del turismo europeo en la España de los años 60

\section{Claves de una oferta turística atractiva}

España aglutinaba una serie de elementos singulares que definieron en el exterior un destino turístico de gran atractivo. Una de las razones de su elección como objetivo vacacional fue el factor de la proximidad. Las primeras oleadas importantes de turistas europeos que llegaron a España a finales de los cincuenta se instalaron en las costas catalanas, las más cercanas a sus lugares de origen. Desde entonces, esta región fue objeto de una intensa afluencia y de una demanda prioritaria, sobre todo entre la población francesa.

En los años sesenta, en plena expansión del parque automovilístico, la carretera se mantuvo como la principal vía de entrada fronteriza y de desplazamiento por el interior de la península. El ferrocarril, que en los años de posguerra había subordinado el tráfico regular de viajeros al transporte de mercancías, arrojaba un índice de crecimiento muy lento $y$, en consecuencia, unos costes sensiblemente superiores a los del transporte por carretera. El avión, aunque en progresivo crecimiento, continuaba siendo un medio turístico limitado. Y, en fin, las compañías españolas encargadas del transporte marítimo de pasajeros en largo recorrido (Transmediterránea, Trasatlántica, Ibarra y Cía, Naviera Aznar S.A.) registraban un volumen estacionario de importancia muy reducida. Este esquema de disponibilidad y utilización del transporte explica la neta preponderancia del turismo europeo sobre el norteamericano y un desarrollo ligeramente más tardío del turismo hacia los archipiélagos.

A pesar de la cercanía geográfica, los habitantes de Europa occidental conocían poco y mal la realidad española. Imágenes fuertemente estereotipadas nutrían la mentalidad colectiva de la época. Si tomamos como ejemplo el caso de Francia, es posible afirmar que la imagen de España era una amalgama de elementos muy diversos, contradictorios incluso, y todos ellos procedentes del pasado. Pervivían ciertas connotaciones de la leyenda negra creada en los siglos XVI y XVII en el contexto de decadencia de la monarquía hispánica: oscurantismo, despotismo, arrogancia, integrismo religioso, aislamiento... A estas percepciones se habían unido las imágenes exóticas difundidas por los viajeros del siglo XIX. Los clásicos del Romanticismo francés, como Chateaubbriand, Mérimée o Gautier, seguían despertando un interés considerable y prueba de ello es la publicación, casi un siglo más tarde, de obras que persistían en la exhibición de España como un país insólito, plagado de contrastes y lugares misteriosos (por ejemplo Images d'Espagne de J. Sermet en 1955 o L'itinéraire espagnol de A. 
Serstevens en 1963). Los escritos más eruditos, con análisis detallados del conjunto histórico y el patrimonio monumental de España (así Nous partons vers l'Espagne de P. Guinard, 1963), tuvieron una difusión mucho menor. Por su parte, el mundo del espectáculo asistió al desarrollo de la españolada o la reducción del patrimonio cultural español a representaciones populares de la Carmen de Bizet, la canción de Luis Mariano, el flamenco y los toros. También la guerra civil despertaba un gran poder de seducción entre el público francés. En palabras del hispanista Jean-Marc Delaunay, «la guerre civile espagnole fut sans aucune doute la période la plus espagnole de l'opinion publique française» ${ }^{4}$. Y es cierto que, varias décadas después del conflicto, las imágenes del drama y la tragedia continuaban vigentes al referirse a España, y la guerra civil, con sus dosis de idealismo y leyenda, era uno de los temas recurrentes en la prensa y en la bibliografía coetáneas.

Con la estrategia utilizada en la promoción exterior del turismo, el régimen franquista contribuyó a consolidar y acentuar esta visión estereotipada ya de por sí dominante en el imaginario europeo. Se produjo, en estos años, un contraste paradójico en la doble forma de proyección de la imagen de España en el extranjero. Por un lado, en el contexto de las primeras demandas para el ingreso en la CEE, los discursos sobre la apertura, la modernidad y el desarrollo económico se habían convertido en la nueva tarjeta de presentación de las más relevantes autoridades políticas (Areilza, Castiella...) y económicas (Ullastres, Navarro Rubio...). Sin embargo, el principio rector de la propaganda turística no fue tanto la venta de la imagen de un país moderno y de vocación europea como la explotación del arcaísmo y las condiciones de vida peculiares de los autóctonos, la restauración de los viejos estereotipos y la simplificación del modelo geográfico y cultural. La propaganda oficial concibió estos aspectos como la mejor forma de diferenciar a España entre los países de su entorno y potenciar, de esta forma, su atractivo turístico. En la exportación del folklore popular, la iconografía se llenó de restos arqueológicos de glorias pasadas, de paisajes agrarios con instantáneas de miseria y de espectáculos religiosos al más puro estilo tradicional. Ruinas, costumbres rurales, productos de la industria artesanal y celebraciones católicas poblaron folletos, guías y reportajes, todos ellos comercializados bajo la etiqueta de «auténtico» para el disfrute de los demandantes de arcaísmo.

Pero, sobre todo, fueron los tópicos andaluces los difusores por excelencia de la imagen turística de España. Al modo del Bienvenido Mr. Marshall de Berlanga, cualquier lugar de la península fue susceptible de convertirse en Andalucía, cubriéndose con estampas típicas, 
de fácil reconocimiento y pervivencia en el subconsciente colectivo. El Paris Match del 16 de septiembre de 1962 introducía un reportaje sobre el ocio de los parisinos con una viñeta humorística muy ilustrativa. En el pie de página podía leerse: "Vous qui avez beaucoup voyagé, quel est donc le pays qui vous a le plus impressionné?». Para referirse a España el dibujo presentaba a los interpelados, vestidos de sevillana y cordobés, tomando unas tapas en un hábitat decorado con los souvenirs importados de su destino turístico preferido: el cartel de una corrida de toros, el póster de un pueblo de fachadas blancas resplandecientes bajo el sol, una guitarra, una pandereta, un abanico, una manta de bandolero y una imagen religiosa ${ }^{5}$.

La convergencia entre la demanda extranjera y la oferta oficial influyó en el conjunto de la población española que, sin posibilidad de escapar al juego de espejos deformantes, acabó por identificarse con toda aquella parafernalia folklórica ${ }^{6}$. A fin de dejar al visitante una impresión muy typical, los espectáculos taurinos, los bares de tapas y los locales destinados al cultivo de un flamenco de ocasión crecieron de forma asombrosa. Tal insistencia en la comercialización turística del estereotipo contribuyó a acentuar la imagen sesgada de España en el exterior, pero también fue la forma más cómoda y más rápida de promocionar las playas y el sol ibéricos frente a la competencia mediterránea ${ }^{7}$.

Porque, en efecto, los habitantes del noroeste de Europa se habían volcado hacia el sur en busca de un antídoto a sus largos, fríos y nublados inviernos. El clima fue otro de los factores que con más fuerza influyeron en la elección de España como destino turístico. La búsqueda de sol y playa se tradujo en una acusada estacionalidad (meses de julio y agosto) y una elevada concentración geográfica (franja costera mediterránea) del fenómeno turístico. Las excepciones fueron Canarias, por sus ventajas climáticas, y Madrid, por ser lugar de paso obligado en la ordenación radial del transporte español.

Otro de los argumentos que reveló efectos positivos en la incitación al viaje a España fue el de sus bajos precios, fruto del incipiente nivel de desarrollo de la economía española, de la política de control de la administración pública y de la entrada en el mercado turístico de las grandes sociedades extranjeras. Los habitantes de los países industriales de Europa occidental pudieron disfrutar en España de servicios comparativamente superiores, en proporción calidad-precio, a los de sus lugares de origen. Además, la oferta oficial de condiciones financieras sumamente favorables animó a los inversores, particulares y empresas, a emprender negocios que resultaron muy rentables a 
corto plazo. A lo largo de los años sesenta, la gran demanda de alojamientos en las zonas turísticas fue seguida de una fuerte inversión en el mercado inmobiliario por parte de los titulares extranjeros, bien para la adquisición de una segunda vivienda, bien para un alquiler o venta rápida portadora de un alto beneficio ante la continua revalorización del suelo. Si el bajo coste de los terrenos, materiales y mano de obra garantizaba unos precios muy bajos de venta al público, la reventa solía superar el $15 \%$ de los fondos invertidos con una plusvalía anual del 30 o $40 \%$ y también los precios de alquiler se incrementaban continuamente.

Ante la penuria del ahorro nacional y la escasa capacidad de maniobra de la iniciativa privada española, las grandes sociedades extranjeras acapararon el mercado turístico interior. Salvo unas pocas excepciones, como Viajes Marsans, Viajes Meliá o Pullmantur, los intentos de organizar agencias de viajes nacionales de tipo mayorista sucumbieron a la férrea competencia de los operadores turísticos extranjeros. Estos monopolios, entre los que el Club Mediterráneo francés constituyó un buen ejemplo, disponían de redes autosuficientes encargadas de la promoción y la organización autónoma del viaje «toutcompris», incluyendo transporte (generalmente en vuelo charter y autobús), alojamiento (a precios muy bajos) y una amplia gama de servicios para el esparcimiento de sus clientes.

\section{Una política oficial de promoción masiva}

El turismo se inscribe en esa facultad de adaptarse a las circunstancias que constituyó, de alguna forma, la práctica no escrita de la actividad exterior del régimen franquista. Los poderes públicos desterraron paulatinamente las medidas restrictivas a la entrada de extranjeros en España. Conforme avanzaba la década de los cincuenta, el interés inicial por la captación de un turismo de lujo cuyos componentes no crearan problemas al régimen, dejaba paso a una política de atracción no selectiva de un turismo colectivo a gran escala. Muy pronto el fenómeno fue considerado como una fuente irremplazable de beneficios a corto plazo. En los sesenta, la preocupación por los ingresos en divisas se convirtió en el factor rector del ordenamiento turístico. El auge numérico de las riadas estivales de turistas-divisas llevó a infravalorar, cuando no ignorar, sus posibles costes económicos y sociales a medio y largo plazo. También barrió los escrúpulos morales, las buenas costumbres y el recato que tanto se habían pregonado. 
La respuesta estatal a la importancia potencial del turismo no se hizo esperar. En septiembre de 1948 apareció el famoso España es diferente, como una mezcla de disculpa y coartada para justificarse en clave internacional y lanzar la semilla de la atracción turística. El Ministerio de Información y Turismo, creado en julio de 1951 y dirigido por Gabriel Arias-Salgado hasta 1962 y por Manuel Fraga Iribarne desde ese año hasta 1969, se convertiría, después del de Gobernación, en el más influyente del país. Poco a poco, los asuntos turísticos invadieron los órdenes del día de comisiones y delegaciones interministeriales, a la vez que se multiplicaban las disposiciones y organismos para la regulación del sector.

El turismo adquirió el rango de industria prioritaria y la trascendencia de cruzada nacional. Para los nuevos dirigentes tecnócratas no había ninguna duda sobre sus posibilidades en el desarrollo económico del país. Convencidos del carácter estructural o sostenido de la demanda, le otorgaron un lugar prioritario en la planificación indicativa que siguió a la estabilización de 1959: en el primer plan de desarrollo (1964-1967) los transportes recibieron el 25\% de la inversión pública y la construcción de alojamientos turísticos el $19,5 \%{ }^{8}$. El turismo abría las puertas a una propaganda convertida, por su aceptación internacional, en una de las mejores garantías para la supervivencia del régimen. Tal parecía ser la percepción de Franco cuando en el mensaje que dirigió a los españoles para inaugurar el nuevo año de 1963 señaló: «Felizmente, los millones de extranjeros que nos visitan a diario son la mejor demostración de las verdaderas condiciones que reinan en el interior de nuestra nación»9. También la Iglesia asumió posiciones cada vez más transigentes frente a la invasión turística. Tuvo que aceptar la imposibilidad de inmunizar permanentemente a los españoles contra los peligros de la novedad extranjera y tuvo que reajustar sus esquemas para frenar una tendencia en ascenso hacia la laicización de la sociedad. Y así, por ejemplo, la "veda hispánica al uso del bikini», regulada en la normativa de la Dirección General de Seguridad de 1958 y respaldada con furia en sermones y letras episcopales, tuvo que ser abolida por unos y otros en la década siguiente. En un intento desesperado por evitar el declive irreversible de la «reserva católica de Occidente», la Pastoral de Turismo intentó reforzar su misión evangelizadora presentando los ritos de la liturgia religiosa a los visitantes extranjeros. Sin embargo, estos apenas diferenciaron el espectáculo exótico de la verdadera religiosidad.

Con una amplia red de organismos repartidos por la geografía española y las principales capitales internacionales (oficinas de turismo, 


\section{Esther M. Sánchez Sánchez}

congresos y asambleas, expotur...), se puso en marcha un dispositivo de propaganda y publicidad destinado a promocionar en el exterior el viaje a España y a convencer en el interior que el turismo constituía un fin nacional e ineludible. En 1965, con ocasión de la entrega de las medallas al mérito turístico, Fraga declaraba: "Es necesario crear y fortificar una verdadera conciencia turística, en la medida en que el turismo es una empresa nacional que exige la colaboración de todos los individuos en el seno de una obra común y constituye una responsabilidad para todos los españoles sin ninguna excepción ${ }^{10}$. La preocupación del ministro se manifestó claramente con aquel baño en la playa de Palomares que inauguró la temporada de 1966.

Los obstáculos administrativos y el control policial para el cruce de aduanas fueron progresivamente suavizados. El visado personal y el tríptico o carné de pasaje exigido a los automóviles que atravesaban los puestos fronterizos quedaron respectivamente reemplazados por el pasaporte y la carta gris, de reducido trámite burocrático. Con todo, la supresión total del visado consular para los franceses, por ejemplo, no se produjo hasta 1966. La fecha resulta sorprendentemente tardía teniendo en cuenta la liberalización creciente de los contingentes comerciales tras la entrada en la OECE y la voluntad proclamada de facilitar al máximo la entrada a los residentes del país vecino. Suponemos que este retraso no puede explicarse tanto por el desconocimiento de las circunstancias y proyectos oficiales como por las reticencias de los consulados a prescindir de unos recursos económicos sustanciales.

En pocos años, se pusieron en funcionamiento diversos organismos públicos y privados destinados a la formación de especialistas: Instituto de Estudios Turísticos (1962), Escuela Oficial de Turismo de Madrid (1963) y escuelas de turismo y hostelería repartidas por las principales capitales de provincia. Apelando al interés nacional, se aprobó un amplio sistema de préstamos, exenciones fiscales, subvenciones a fondo perdido y otros privilegios como la expropiación forzosa y donación subjetiva de terrenos e inmuebles para obras turísticas. El crédito hotelero, creado en 1942, se convirtió en crédito turístico en julio de 1963, ampliando las posibilidades del sector. Los municipios incluidos en la Ley de Centros y Zonas de Interés Turístico Nacional de 1963 recibieron ayudas diversas para la construcción y el acondicionamiento de infraestructuras con proyección turística. Entre estas ayudas, el Banco Hipotecario se encargó de financiar las edificaciones destinadas a la venta a extranjeros. Reactualizando un proyecto de los años veinte, el estado creó en abril de $1952 \mathrm{su}$ propia cadena de alojamientos de lujo destinados 
a cubrir los vacíos turísticos del interior del país (Red Nacional de Paradores y Albergues). En este aspecto, el dinamismo de Fraga era excepcional hasta el punto de que si la estampa más típica del quehacer oficial había sido en los años cincuenta la de Franco inaugurando pantanos, la de los años sesenta era la de Fraga inaugurando paradores. El camping, objeto de trabas sistemáticas en los años cuarenta y cincuenta por principios de seguridad, moralidad y orden público, hubo de ser finalmente aceptado ante el gran incremento de la demanda. En el intento de presentar al país en condiciones de competencia que representaran otro acicate para los europeos, el gobierno estableció en septiembre de 1962 una «operación precios» basada en la fijación de un máximo y un mínimo que garantizasen el bajo coste de los servicios, operación que afectó fundamentalmente al sector de la hostelería. Desde 1964, los riesgos de accidente, enfermedad y problemas jurídicos del viajero extranjero quedaron cubiertos por el denominado Seguro Turístico Español.

El estado participó directamente como empresario en el sector a través de dos organismos: la Administración Turística Española -ATE-, encargada de la gestión de rutas, paradores y albergues, y el INI, al que pertenecían, entre otras sociedades, Autotransporte Turístico Español S.A. -ATESA-, Aviación y Comercio S.A. -AVIACO-, Líneas Aéreas Españolas S.A -IBERIA-, Empresa Nacional de Turismo S.A. -ENTURSA- y la empresa nacional de artesanía Artespaña. Por las vías legislativa y consuetudinaria, el estado se impuso a la iniciativa privada nacional acaparando en control monopolístico o mayoritario las principales empresas y actividades relacionadas con el sector. Sin embargo, las trabas a la inversión exterior fueron pronto suprimidas. Desde 1963, se autorizó la libre entrada de capital extranjero en todas las actividades relacionadas con el sector turístico, el cual quedaba incluso liberado de la obligación general de contar con una autorización del Consejo de Ministros en las inversiones que superasen el 50\% del capital de las empresas nacionales.

Ningún otro sector de la economía española arrojaba cifras comparables a las del turismo y cualquier pretexto era válido para el despliegue de extraordinarias campañas propagandísticas, así la entrada del turista uno, diez o veinte millones, el día anual del turista que tuvo su primera celebración el 5 de septiembre de 1964, el aniversario en esa misma fecha de los 25 años del franquismo («de paz» según la terminología oficial) o la conmemoración en 1967 del año internacional del turismo bajo un eslogan que venía de perlas al régimen: «el turismo, pasaporte para la paz». 
Por su posición mundial, España fue llamada a incrementar la cooperación bilateral y multilateral en materia turística. Las oficinas de turismo instaladas en las principales capitales del mundo sirvieron de trampolín a la cooperación bilateral. Por otra parte, España fue miembro de las más importantes organizaciones turísticas internacionales, algunas permanentes y generales, como la Unión Internacional de Organismos Oficiales de Turismo (UIOOT), la Comisión Europea de Turismo (CET) o el Comité de Turismo de la OECE, y otras temporales y de temática específica, así el Comité de Montparnasse, reunido en Paris en octubre de 1967 para organizar la cooperación técnica en materia aérea.

\section{Un contexto internacional propicio}

Las circunstancias exteriores resultaron, por otra parte, sumamente favorables a la hora de impulsar y asegurar la continuidad del turismo español. Uno de los factores definitorios del progreso económico y del cambio social experimentado por Europa occidental tras su reconstrucción fue el incremento del tiempo de ocio. El aumento de los índices de renta y la capacidad de consumo entre amplias capas de la población llevó a sentar como imprescindibles gastos que en otro tiempo ocupaban un lugar secundario o se clasificaban en la categoría de superfluos: en la ordenación del presupuesto familiar, las vacaciones (pagadas) alcanzaron estratos cercanos a la alimentación o el vestido. La nueva industria del ocio con destino al extranjero, ampliamente difundida en los medios de comunicación, reveló pronto su capacidad para satisfacer los deseos de consumo de la creciente clase media y procurar, bajo la forma de una evasión hacia el exotismo y el descanso, una salida al carácter uniforme, monótono y agotador de la sociedad industrial y de la vida urbana. España aparecía ante sus ojos como el destino ideal: cercano, barato, exótico, amable, tranquilo y con buen clima. Se recuperó, en cierta forma, a aquellos románticos que proyectaron su viaje a España como una huida de la naciente revolución industrial y urbana que se desarrollaba en la Europa del siglo XIX. La trayectoria era la misma, de norte a sur, en dirección opuesta a la emigración, pero las circunstancias históricas, el volumen, las características y los efectos de una y otra corriente fueron radicalmente distintos.

Volviendo a los años sesenta del siglo XX, es posible afirmar que también el contexto geopolítico mundial influyó indirectamente en el incremento del turismo extranjero con destino a España. La guerra fría situó a las dos superpotencias en el centro de las miras internacionales. En estas circunstancias, comenzó a desarrollarse un nuevo 
El auge del turismo europeo en la España de los años 60

tipo de antifranquismo desapasionado, que consideraba al régimen como poco deseable pero que admitía su existencia como hecho menor $\mathrm{y}$ consumado, a la vez que reconocía y hacía uso de su utilidad estratégica en la defensa de los intereses occidentales. De esta forma, la cuestión de la democratización interior de España quedó relegada en los foros internacionales y la naturaleza dictatorial de su régimen político acabó por obviarse entre la opinión pública, librando de obstáculos su elección como destino vacacional.

El análisis específico del ejemplo francés proporciona información interesante sobre las características demográficas, socioeconómicas y culturales del turista extranjero en España. Los desplazamientos registrados entre la población del país vecino fueron mayoritariamente colectivos, en grupos de amigos o en familia. Por lo general, las fórmulas del viaje organizado propuestas por los operadores turísticos no tuvieron tanto éxito como en otros mercados emisores, el inglés o el alemán por ejemplo. Aunque sin ningún apoyo estadístico, los informes emitidos por las autoridades económicas francesas hacen referencia a jóvenes y familias con hijos pequeños, de lo que podría deducirse un intervalo prioritario de edades comprendidas entre los 20 y los 40 años ${ }^{11}$. Por categorías sociales, destacaron los cuadros superiores y profesiones liberales, cuya tasa media anual de desplazamientos, con España como uno de los destinos más solicitados, aumentó de 62 a $90 \%$ entre 1960 y 1969. El porcentaje de obreros experimentó un incremento progresivo del 21 al 46\%, mientras que los trabajadores del sector primario no superaron el $10 \%$ durante el mismo intervalo ${ }^{12}$. La región parisina aparecía como el centro principal de emisión de veraneantes, con un porcentaje del $76 \%$ sobre el resto de las regiones francesas ${ }^{13}$. La convergencia entre condiciones climáticas y vacaciones escolares o profesionales determinó la preferencia por los meses de verano, registrándose las máximas en agosto. Para la entrada en España se utilizaron fundamentalmente las carreteras transpirenaicas y los vehículos particulares. La documentación francesa señala que los principales puestos fronterizos francoespañoles (La Junquera, Le Perthus, Irún-Hendaya y Cerbère-Port-Bou) registraban, en temporada alta, una media cercana a los 10.000 turismos al día ${ }^{14}$. Los veraneantes franceses se asombraban al comprobar que los atascos de la carretera de la Costa Brava superaban a los de las autopistas de entrada a París un domingo por la tarde ${ }^{15}$.

Las estadísticas del Ministerio español de Información y Turismo confirman estos datos. En 1964, por ejemplo, se contabilizaron 10.507.000 entradas de extranjeros provistos de pasaporte, de los cuales 5.477.000 eran franceses. Desglosando la última cifra, obtenemos un 
total de 4.996.000 de turistas entrados por carretera, de los cuales 2.643 .000 lo hicieron durante los meses de julio y agosto ${ }^{16}$. La duración media de la estancia osciló entre algo menos de una semana si el alojamiento se realizaba en hoteles o pensiones, y algo más de dos semanas si se optaba por la residencia extra-hotelera: apartamentos, campings, alojamiento en casa de los residentes... A medida que el turismo alcanzaba a capas más amplias de la población y se extendía entre las clases más populares, la residencia extra-hotelera incrementaba sus índices de afluencia. Si en la publicidad de las agencias de viajes francesas los turistas eran invitados a alcanzar cuanto antes el litoral, la realidad no hizo sino confirmar el éxito de esta convocatoria. El resto del país se visitaba, si acaso, en rápidas incursiones que proporcionaban una idea muy limitada del mismo. El registro hotelero señala que la zona de mayor demanda y afluencia fue la Costa Brava, percibiéndose, además, una irradiación relativamente importante hacia el sur, esto es, hacia la Costa Dorada, la Costa Blanca y la Costa del Sol. El litoral atlántico fue objeto de una afluencia mucho menor, con algunas excepciones. Sirva de ejemplo el pueblo de Laredo en la provincia de Santander, que en temporada alta podía llegar, según los testimonios de sus contemporáneos, a triplicar su población con la llegada de franceses ${ }^{17}$.

En líneas generales, España fue un centro de recepción de un turismo barato, sedentario, poco exigente y de curiosidad superficial. El grueso de los visitantes llegó en busca de unas vacaciones al sol con prestaciones de calidad básica y a precio reducido. Aunque el sesgo estadístico hace imposible establecer una evaluación precisa del gasto medio del turista extranjero en España, es posible afirmar que el gasto medio de los europeos, en general, y de los franceses, en particular, fue sensiblemente inferior al de los norteamericanos. Sin embargo, su importancia numérica determinó unos índices ampliamente superiores de ingresos en divisas. Los informes franceses señalan, respecto a sus nacionales, sumas anuales de 250 a 300 millones de dólares sobre un total de $500^{18}$. Para los residentes del país vecino, los bajos precios constituían también un destacado atractivo para la compra de propiedades inmobiliarias: "on peut fournir en Espagne pour 30.000 francs un appartement que l'on ne trouvera pas pour 100.000 sur la Côte d'Azur» ${ }^{19}$. A ello se sumaba la serie de facilidades otorgadas por el régimen franquista a la entrada de capitales extranjeros: "L'Espagne ne semble faire aucune difficulté aux achats. On apporte les devises, elle les prend $\gg^{20}$.

Por su parte, la política económica de la $\mathrm{V}$ República francesa puso en funcionamiento diversos mecanismos para favorecer la movilidad del ahorro privado, con lo que las posibilidades de inversión se 
extendieron a capas cada vez más amplias de la población. Los anuncios publicitarios y reportajes sobre la inversión inmobiliaria en España inundaban la prensa francesa de la época. Era frecuente jugar con el significado literal y figurado de la expresión "bâtir des châteaux en Espagne» para concluir que "construir castillos en España» había perdido sus connotaciones utópicas y se había convertido en algo accesible. Algunas agencias inmobiliarias vendían en francos desde París, previo pago de un viaje gratuito al comprador potencial para supervisar el estado de la construcción. Carecemos, sin embargo, de cifras que definan de forma más precisa el alcance del fenómeno. Por un lado, la discreción regía la actividad de promotores y constructores en el intento de evitar escollos legales que, de otro modo, hubieran hecho naufragar su empresa. Por otro lado, los compradores particulares intentaban por todos los medios no figurar como propietarios para evadir el fisco español, ya que del francés se libraban automáticamente con la convención franco-española sobre las dobles imposiciones, que obligaba a declarar únicamente en el país donde estaba situado el inmueble.

A pesar de la importancia de los viajes culturales en el origen del turismo extranjero con destino a España, en los años sesenta la demanda siguió los pasos de la oferta franquista y centró sus miras en el estereotipo y en la vertiente más kitsch y pintoresca del patrimonio español. La oferta histórico-artística no parecía ser un gran incentivo entre la población francesa de la época. En 1967, una encuesta del INSEE (Institut National de la Statistique et des Etudes Economiques) sobre la ocupación del tiempo de ocio en Francia señalaba que, en ese año, sólo el $18 \%$ de los entrevistados había visitado un museo y un $30 \%$ un castillo o monumento ${ }^{21}$. Los resultados de esta investigación se corroboran con las conclusiones paralelas de los analistas españoles: "El francés que ha visitado una vez Avila no vuelve a ella. Si vuelve será como inquilino de los apartamentos de Tossa de Mar» ${ }^{22}$.

¿Cómo conjugar las características ideológicas del régimen español con la afluencia masiva de ciudadanos procedentes de los países democráticos de Europa occidental? Al término de la segunda guerra mundial, las potencias occidentales habían proclamado abiertamente su rechazo al régimen de Franco. En Francia, el cierre de la frontera con España en 1946 había sido apoyado por casi la mitad de la opinión pública $(47 \%)^{23}$, resuelta a acabar con el último vestigio del fascismo para borrar la sombra del régimen colaboracionista de Vichy y el recuerdo de su pasividad en el desenlace de la guerra civil española. Pero el contexto era diferente en los años sesenta. En la nueva geoestrategia mundial, Francia buscó el equilibrio con las grandes potencias 


\section{Esther M. Sánchez Sánchez}

y se sumó a la extensión general del desinterés hacia España. El desplazamiento de la cuestión española en los programas del Quai d'Orsay y la falta de atención en los medios de comunicación contribuyeron a la aceptación implícita de la dictadura, a menudo considerada, simplemente, como otra más de las diferencias pintorescas del país.

España fue ante todo un lugar de descanso y evasión. La pequeña potencia, el vecino pobre del sur, no tenía cabida entre los objetivos de Grandeur del gobierno francés, pero conservó un gran atractivo como destino turístico, y ello explica que la única visita del general de Gaulle se realizara en 1970, una vez retirado de la vida pública. Si esta desatención política jugó en benefició del turismo, también lo hizo en contra de la curiosidad no estrictamente turística por la realidad española. Si a ello sumamos las dificultades lingüísticas, las diferencias de costumbres y modos de vida, la escasa movilidad geográfica de los veraneantes, la permanencia en el grupo y un cierto sentimiento de superioridad en la mirada del desarrollado hacia el subdesarrollado, es posible advertir la ausencia de una integración efectiva entre visitantes y autóctonos, lo cual se tradujo en el mantenimiento de la visión sesgada y estereotipada de la realidad española. Este distanciamiento no sólo se explica por la fugacidad de las estancias turísticas, puesto que también era la pauta dominante entre los franceses que trabajaban de forma permanente en España, ocupando, por lo general, puestos directivos con unos salarios sensiblemente superiores a los nacionales.

El auge sostenido del turismo español iba a jugar en contra del país vecino. El declive de los índices de entrada de extranjeros en Francia se agravó con el incremento de las salidas de franceses hacia España, produciéndose un importante trasvase de divisas. Las autoridades francesas se vieron obligadas a actuar en consecuencia. En la búsqueda de causas explicativas del descenso de la frecuentación extranjera, los informes elaborados por el Ministerio de Economía y Finanzas coincidían al subrayar la restricción geográfica del sol, el alto nivel de precios y el mal estado de las infraestructuras hoteleras: "(...) même si en dehors de la côte d'Azur, il est difficile à notre pays de concurrencer le soleil de la péninsule ibérique, les sommes laissées par les français en Espagne sont extrêmement importantes et méritent d'être signalées aux autorités compétentes pour qu'un effort soit fait en matière d'hôtellerie (confort et prix) » ${ }^{24}$. Los altos precios fueron objeto de continuas campañas de propaganda negativa hacia Francia, las cuales favorecieron de forma indirecta el viaje a España. Así, en 1964, con ocasión de la inauguración de un ferry para el transporte de automóviles y pasajeros de Southampton à Santander, una sociedad inglesa 
lanzó un eslogan que exhortaba a prescindir del itinerario francés para restringir gastos: "Eviter la traversée de la France. Faites des économies ${ }^{25}$. La respuesta de las autoridades y los medios de comunicación franceses fue, desde mediados de los sesenta, el lanzamiento de una cierta política tendente a poner de relieve que España ya no era el país más barato de Europa ${ }^{26}$.

\section{El turismo como motor de expansión económica y agente de cambio sociológico}

¿Cómo medir los resultados económicos y sociológicos del fenómeno turístico en España? En los años sesenta, el auge numérico inundó la producción literaria, plagándola de análisis excesivamente triunfalistas, subjetivos y superficiales. La prensa oficial, los informes anuales del Ministerio de Información y Turismo, las publicaciones periódicas de la Escuela Oficial de Turismo o el monográfico de Información Comercial Española publicado en septiembre de 1968 dan buena prueba de ello. La bibliografía posterior contribuyó a un mejor conocimiento del impacto del turismo en la economía española, al relativizar la importancia de las cifras (Cals, Jurdao Arrones... ${ }^{27}$ ) e insertar el caso español en el contexto mundial de desarrollo del turismo de masas (Fernández Fuster, Valenzuela... ${ }^{28}$ ). La obra colectiva 50 años de turismo español. Un análisis histórico y estructural, de reciente publicación ${ }^{29}$, realiza una completa revisión y puesta al día del tema, aunque con atención prioritaria a sus efectos económicos y a las dos últimas décadas del siglo. A pesar de la prodigalidad del tema, carecemos aún de estudios que hayan evaluado en profundidad los efectos del turismo en el cambio de mentalidad de la sociedad española contemporánea, y también de análisis que transciendan la dinámica interior para insertar el fenómeno turístico en el plano de las relaciones internacionales.

El impacto del turismo sobre la economía española es difícil de establecer. Su evaluación precisa se enfrenta a varios obstáculos: el sesgo y subjetividad de las estadísticas oficiales españolas ${ }^{30}$, el volumen del mercado monetario oculto y la dificultad de separar la parte de la producción y del consumo correspondientes a turistas y a autóctonos. El crecimiento de las cifras debe ser, en fin, relativizado teniendo en cuenta su bajo nivel de partida. En cualquier caso, es evidente que, junto a las remesas de emigrantes y a las importaciones netas de capital por inversiones, el turismo aportó una financiación exterior decisiva para el desarrollo de la economía española en el decenio de 1960. 
La llegada masiva de extranjeros se tradujo en una entrada considerable de divisas en la balanza de pagos, cubriendo cerca del $75 \%$ del déficit de la balanza comercial y facilitando los medios de financiación de ciertas importaciones (en su mayoría bienes de equipo), sin las cuales no se hubiera producido el nivel de desarrollo alcanzado. De 1958 a 1973, los informes anuales de la OECE-OCDE señalaron a España como el país europeo con mayor dependencia de las divisas por concepto turismo en la balanza de pagos. Según estos informes, las remesas de los emigrantes no superaron el 25\% de los ingresos turísticos, si bien estudios posteriores incrementaron este porcentaje hasta una media de un 35 o $40 \%{ }^{31}$. Tampoco los totales de la inversión extranjera alcanzaron en la década de los sesenta el volumen de divisas procedentes del turismo. Estudios coetáneos y actuales coinciden al afirmar que los ingresos representaron más de catorce veces el valor de los pagos, pues el porcentaje de salidas de turistas españoles al extranjero, aunque en neta progresión, fue mucho menor que de las entradas de extranjeros en España.

En definitiva, por su efecto multiplicador o intersectorial, los efectos del turismo afectaron al conjunto de la economía española, dando un impulso considerable al proceso de homologación con las economías occidentales. Muchos otros sectores económicos se beneficiaron de las inversiones nacionales y extranjeras dirigidas en prioridad al sector turístico, así la construcción, la hostelería, el transporte, las agencias de viaje, las actividades recreativas o el comercio. Las zonas turísticas presenciaron una rápida transformación de su paisaje urbano y demográfico, gracias a la expansión de las infraestructuras, la mejora de los servicios públicos y la ampliación del mercado de trabajo.

Las cifras del sector turístico reflejaron la abierta discordancia entre planificación y realidad que condujo a economistas e historiadores a considerar los planes de desarrollo como una mera plataforma de propaganda de la acción gubernamental. Los resultados iniciales del primer plan de desarrollo hablan por sí solos: en 1964, el incremento de la entrada de divisas con respecto a 1963 fue de $39,2 \%$ frente a una predicción del 10,9\% y la construcción de viviendas alcanzó el $25 \%$ frente al $8 \%$ señalado en el plan $^{32}$. Sin capacidad ni rapidez de respuesta para planificar a medio y largo plazo la evolución del fenómeno turístico, las autoridades franquistas se limitaron a propulsar la progresión matemática de visitantes y divisas. El ritmo de crecimiento acelerado unido a la ausencia de una gestión acorde con los principios de un desarrollo equilibrado produjo consecuencias de difícil solución inmediata e incluso situaciones de degradación irreversibles. Después de 
El auge del turismo europeo en la España de los años 60

unos años de apogeo, el turismo sufrió las consecuencias de un cierto estancamiento de la economía europea. Las cifras se frenaron hacia 1967-68, se recuperaron levemente en los años siguientes y sucumbieron a los efectos de la crisis mundial de 1973, cuyo eco llegó hasta principios de los años ochenta. Por otro lado y de forma paralela al crecimiento sostenido del número de visitantes, se observa una progresiva disminución del gasto medio por turista y por año, fenómeno derivado, fundamentalmente, de la convergencia de la política gubernamental de salvaguardia de precios, de una cierta reducción de la capacidad de gasto del turista medio y de una tendencia progresiva al cambio de moneda en su propio país. La reducción de los porcentajes de entrada de divisas en la balanza de pagos agravó y sacó a la luz los efectos negativos que el turismo había venido produciendo en el paisaje y la economía:

- En la lucha por asegurar una posición de fuerza en el mercado y llevando al extremo la política del beneficio fácil y a corto plazo, la construcción de inmuebles pasó por alto los criterios mínimos de racionalidad, dejando un deterioro ecológico considerable y una geografía de acusados contrastes entre el hacinamiento de la costa y el empobrecimiento interior. En la práctica, la promoción franquista insistió demasiado en motivos de atracción que no hicieron sino reforzar la estacionalidad y la concentración geográfica de la demanda. Las costas se llenaron de especuladores y de torres verticales. La concentración y la devastación de amplias zonas del litoral provocaron una reducción sensible de la calidad del equipo receptivo y, con ello, un efecto contrario al esperado: la recuperación de la competencia.

- El grueso de los beneficios fue a parar, por un lado, a los operadores turísticos y a las sociedades inmobiliarias extranjeras y, por otro lado, a las regiones periféricas nacionales que poseían de antemano un cierto grado de desarrollo industrial (Cataluña). Otros puntos periféricos asistieron a una elevada inversión en infraestructuras y a un gran avance del sector terciario sin la previa modernización agrícola e industrial (Andalucía). En fin, buena parte de las regiones del interior mantuvieron su estancamiento, a menudo agravado con el éxodo rural (Extremadura, Castilla o Aragón). El crecimiento de Madrid en la época no debe tanto al auge turístico como a la concentración de las redes económicas y financieras nacionales e internacionales.

- Oleadas de manchegos, castellanos y aragoneses emigraron a las zonas de costa en busca de un jornal seguro en el abanico de servicios a los que daba lugar aquella masiva llegada de 


\section{Esther M. Sánchez Sánchez}

extranjeros. Los sectores que absorbieron el porcentaje más alto de mano de obra fueron la construcción y los transportes. Se trataba, sin embargo, de trabajadores intermitentes, mal pagados y sin ningún requerimiento de experiencia previa. La extensión del empleo precario contribuyó, con la emigración a Europa, a enmascarar el problema del paro, transmitiendo en el interior y en el exterior una imagen engañosa de la prosperidad nacional.

Junto a sus consecuencias económicas, el turismo extranjero desempeñó un papel considerable en la transformación de la sociedad española. Si los turistas se dedicaron al descanso y la evasión, se desinteresaron de la política y apenas se percataron de la evolución económica y social que estaba teniendo lugar a su alrededor, la población española no fue inmune a la presencia masiva de extranjeros. Contrariamente a la imagen de inmovilismo y atraso anclada en el subconsciente colectivo europeo y reforzada por la propaganda turística oficial, España había comenzado a cambiar. El turismo dio un gran impulso a este cambio. Permitió a los españoles asomarse a lo que estaba ocurriendo al otro lado de las fronteras, traspasando la imagen filtrada, manipulada y ajustada a los intereses políticos que los medios de comunicación se habían encargado de trasmitir a los hogares españoles. Habían sido demasiados los años de puritanismo y represión.

El espectáculo de libertad que inundó las playas y discotecas españolas, las nuevas pautas de actuación social, moral y cultural $y$, en suma, el acercamiento a las formas de vida de las sociedades educadas bajo sistemas democráticos provocaron una auténtica revolución en las mentalidades, sobre todo entre los sectores más jóvenes. La presencia de la juventud europea en plena época de la liberación sexual, del inconformismo, de la ruptura generacional, de la indiferencia religiosa, de la emancipación femenina y de la gestación del mayo del 68 hizo que la juventud española se replanteara los esquemas de valores integristas inculcados por sus progenitores y por la Formación del Espíritu Nacional. Pronto equiparó su forma de vestir y sus ídolos musicales a los de los jóvenes europeos, cambió sus conceptos sobre el amor, el matrimonio y la familia, comenzó a demandar libertades y a salir al extranjero. En definitiva, la intermediación pasiva del turismo extranjero aceleró el contacto de la población española con el exterior, activando sus deseos de homologación con el resto de Europa y atenuando los extremismos en favor de la prudencia, el equilibrio y el diálogo. La impregnación de esta serie de valores ajenos al sistema político vigente jugará en beneficio de la liquidación pacífica de la dictadura. 


\section{El auge del turismo europeo en la España de los años 60}

\section{A título de recapitulación}

El análisis del turismo como factor de las relaciones exteriores del régimen franquista obliga a trascender la hegemonía tradicional de la historia política y diplomática para incluir aspectos económicos, sociales y culturales. Las páginas que anteceden nos llevan a concluir que el turismo contribuyó a la inserción internacional del régimen franquista:

- como instrumento legitimador de la dictadura. El turismo consolidó el proceso de aceptación internacional iniciado con el desbloqueo diplomático y la progresiva incorporación a los organismos internacionales. El registro millonario de visitantes sirvió al sistema político español para justificar su existencia y asegurar su continuidad ante la opinión pública mundial. El trasvase de intereses producto de la guerra fría, la creciente masificación y popularización de la práctica turística, el poder de atracción de la oferta española y las formas de la propaganda franquista llevaron a la aceptación general del régimen dictatorial en tanto que elemento secundario o incidente menor.

- como forma de acrecentar el reconocimiento de España en el exterior. El turismo difundió una serie de estereotipos que expresaron con fuerza la imagen de España fuera de sus fronteras, permitiendo su situación inmediata en el mapa. La contrapartida fue la pervivencia de una visión sesgada y distorsionada, la divulgación de una impronta pseudo-cultural, el encubrimiento de la evolución económica y sociológica coetánea y, en definitiva, la prolongación de una ignorancia cuyos ecos superaron en el tiempo a la dictadura franquista.

- como agente acelerador del cambio sociológico. Los turistas fueron los intermediarios a través de los cuales la población española tuvo acceso a la realidad política, económica, social y cultural del mundo occidental. No ejercieron un papel activo en la transmisión de sus modos de vida, pero su presencia masiva y regular en el territorio español provocó un auténtico cambio en las mentalidades. La mezcla de indiferencia y resignación anclada en la práctica colectiva en los años oscuros del franquismo dejó pasó, sobre todo entre la juventud, a un nuevo deseo por conocer y participar del nivel de vida, del abanico de libertades y del grado de tolerancia presentes al otro lado de la frontera. El turismo limó los extremismos e introdujo unas pautas de estabilidad, entendimiento y comprensión entre los pueblos que 
resultaron decisivas a la hora de la plena normalización de las relaciones exteriores de España en la etapa democrática.

- como instrumento de integración económica. El turismo fue una fuente básica de financiación del desarrollo económico español. A lo largo de los años sesenta, el volumen de divisas aportado por los visitantes extranjeros dejó saldos favorables en la balanza de pagos, compensó el déficit histórico de la balanza comercial y permitió la compra de los bienes de equipo necesarios a la industrialización del país. Pese a la introducción de una serie de distorsiones económicas que se han dejado sentir hasta épocas muy recientes (crecimiento sectorial, dependencia extranjera, empleo precario...), el turismo desempeñó una función estructural de gran importancia por su contribución al incremento del nivel de vida de la población española.

- como instrumento de integración institucional. El turismo impulsó la desaparición de los filtros interiores que impedían la libre y completa relación con los organismos extranjeros y adiestró a los especialistas españoles en el ejercicio del trabajo inter-institucional. Conforme al desarrollo del sector, los organismos nacionales se vieron obligados a entablar contactos con las instituciones turísticas de los mercados emisores, lo cual les llevó a participar en eventos conjuntos (ferias, reuniones, congresos, exposiciones, proyectos de cooperación bilateral y multilateral...) y actuar en consonancia con sus formas jurídicas, financieras y comerciales.

Tras el fin del franquismo, la política turística, progresivamente descentralizada, se orientó hacia parámetros más cualitativos, tendentes al desarrollo económico y social sobre la base del equilibrio ambiental y la rentabilización del papel del turismo como factor para la gestión de los recursos naturales y culturales. La mayor segmentación de los períodos vacacionales, el incremento del turismo interior y el redescubrimiento de los valores diferenciales de los destinos alternativos (cultura, naturaleza, deportes, salud, congresos, parques temáticos...) paliaron la estacionalidad y la concentración geográfica. Los beneficios se extendieron a zonas geográficas tradicionalmente marginadas y un buen número de empresas nacionales accedió al mercado en situación de competir con las grandes sociedades extranjeras. Sin embargo, el turismo de sol y playa siguió siendo prioritario y continuó la difusión de los viejos estereotipos y el aprovechamiento de las tradicionales ventajas comparativas del país. Las formas que caracterizaron al turismo en los años sesenta se habían enraizado con fuerza en la demanda. 


\section{El auge del turismo europeo en la España de los años 60}

\section{Notas}

1 Vid. Fernández Fuster, Luis: Historia general del turismo de masas. Madrid, Alianza, 1991, pp. 629-630.

2 El primer establecimiento, el Castellana Hilton de Madrid, fue inaugurado en 1953. Vid. Felipe Gallego, Jesús: «Hoteles», en 50 años de turismo español. Un análisis histórico y estructural. Madrid, Centro de Estudios Ramón Areces, 1999, pp. 877-898.

3 Conjunto de datos recogidos por el Servicio de Estadística del Ministerio de Información y Turismo. Las cifras comprenden los extranjeros provistos de pasaporte (78\%) los visitantes con un pase de 24 horas (6\%), los viajeros en tránsito portuario (9\%) y los españoles residiendo en el extranjero (7\%).

4 Delaunay, Jean-Marc: Images et influences de l'Espagne dans la France contemporaine. Béziers, P.U. de Perpignan, 1994, p. 41. Las mismas consideraciones en ANGOUSTURES, Aline: "L'opinion publique française et l'Espagne, 1945-1975", Revue d'histoire moderne et contemporaine, $\mathrm{n}^{\circ}$ XXXVII (1990), pp. 672-682 y en MORENO JUSTE, Antonio: "La permanencia de la imagen tradicional de España en Europa occidental tras la II guerra mundial", en La política exterior de España en el siglo XX. Actas del congreso celebrado en Madrid, 10-13 de diciembre de 1997. Madrid, UNED, 1997, pp. 367-378.

5 Paris Match, 16/IX/62, p. 1. Archivo del Ministerio español de Asuntos Exteriores (AMAE-E), R-9623/5.

6 Vid. LAMO DE EsPINOSA, Emilio: «La mirada del otro. La imagen de España en el extranjero", Información Comercial Española, n 722 (1993), pp. 11-25.

$7 \mathrm{El}$ duelo Italia-España fue una constante en los órganos de gobierno y la prensa de ambos países. La documentación conservada en el Archivo General de la Administración (AGA) -sección cultura, subsección turismo- da buena prueba de ello.

8 «Informe de la OCDE sobre España, 1968», Información Comercial Española, (1969), pp. 73-147. Cit. RomAN, Manuel: Los límites del crecimiento económico en España, 1959-1967. Madrid, Ayuso, 1972, p. 63.

9 Pensamiento político de Franco. Antología. Madrid, Ediciones del Movimiento, 1975, p. 681 .

10 Pueblo, 6/XII/65. Cit Poutet, Hervé: Images touristiques de l'Espagne. De la propagande politique à la promotion touristique. Paris, L'Harmattan, 1995, p. 192.

11 «Rapport sur la saison touristique en Espagne». Carta del agregado financiero de la embajada de Francia en España al Ministerio francés de Economía, Madrid, 1/IX/62. Archivos del Ministerio francés de Economía, Finanzas e Industria (AMEFI), B-10840.

12 CARON, François: Histoire économique de la France, XIX-XX siècles. Paris, Armand Colin, 1995 ( $2^{\mathrm{a}}$ ed.), p. 179.

13 L'Aurore, special vacances, 21/VI/65. AGA-cultura, 19740.

14 Carta del agregado comercial de la embajada de Francia en España al Ministerio francés de Economía, Madrid, 1/IX/62. AMEFI, B-10.840.

15 "Ce qui vous attend cette année en Espagne», Le Journal du Dimanche, 21/VI/65. AGA-cultura, 19740.

16 Servicio de Estadística del Ministerio de Información y Turismo. Estadísticas de turismo, año 1964. Madrid, Ministerio de Información y Turismo, 1965.

17 Carta del presidente de la "Amicale des Estivants Français à Laredo" al embajador de Francia en España, Laredo, 6/XI/62. AMEFI, B-10840. 


\section{Esther M. Sánchez Sánchez}

18 Carta del agregado comercial de la embajada de Francia en España al Ministerio francés de Economía, Madrid, 30/X/61. AMEFI, B-43847.

19 "Après les Allemands et les Hollandais, les Français achètent leurs châteaux en Espagne", France-soir, 3/IV/65. AGA-cultura, 19742.

20 Carta del presidente de la "Amicale des Estivants Français à Laredo", doc. cit.

21 Py, Pierre: Le tourisme. Un phénomène économique. Paris, La Documentation Française, 1992, p. 23.

22 GoNZÁlez, Nazario: «Reflejos del turismo español en 1964», Razón y Fe, nº 170 (1964), p. 240.

23 Institut Français d'Opinion Publique: «La question espagnole», Sondages, 16/XII/46, pp. 255-259.

24 Rapport sur l'Espagne. Reuniones consulares de 4 y 5 de diciembre de 1961. AMEFI, B-43 864.

25 RECHE, Albert: "Où en est notre tourisme?», Sud-Ouest, Bordeaux, 5/N/64. AMAE-E, R-9623/5.

26 "Resumen sobre el ambiente general de la prensa en relación con España». Informe de la Oficina de Turismo en París al Ministerio de Información y Turismo, junio 1965. AGA-Asuntos Exteriores, 11526.

27 Vid. CALS, Joan: Turismo y política turística en España. Una aproximación. Barcelona, Ariel, 1974 y JURDAO ARRONES, Francisco: Los mitos del turismo. Paris, Endymion, 1992.

28 Vid. FERNÁNDEZ Fuster, Luis: Historia general del turismo de masas. Madrid, Alianza, 1991 y VALENZUELA, Manuel.: "Spain: the phenomenon of mass tourism", en William, A.M. y SHAW, G: Tourism and Economic Developpement: Western European Experiences. London, Belhaven Press, 1988, pp. 40-60.

29 VVAA: 50 años de turismo español. Un análisis histórico y estructural. Madrid, Fundación Ramón Areces, 1999.

30 Los servicios estadísticos del Ministerio de Información y Turismo registraron mensualmente las entradas fronterizas de los turistas extranjeros, clasificándolos según nacionalidad y vía de paso. El Instituto Nacional de Estadística realizó la contabilidad mensual de las pernoctaciones realizadas en las distintas categorías de establecimientos hoteleros y, desde 1966, también en los campings. La información puede completarse con los datos de las estadísticas generales sobre la evolución de la economía española publicadas por los ministerios de Economía e Industria, el INI y los grandes bancos.

31 VIÑAS, Angel et allii: Política comercial exterior de España (1931-1975), tomo 3. Madrid, Banco Exterior de España, 1979, p. 1.343.

32 "Note d'Information sur le Plan de Développement espagnol des deux premières années d'exécution (1964-65) et problèmes à résoudre au cours de la seconde période 1966-67». AMEFI, B-55299. 